\title{
Compassion Fatigue and Coping Skills of Philippine National Police First Responders in Bacolod City
}

\author{
Miguel R. Lim ${ }^{1}$ and Jasmin L. Parreño ${ }^{2}$ \\ ${ }^{1}$ Real Estate Brokerage, Denver, Colorado, United States of America \\ 2University of Negros Occidental-Recoletos, Bacolod City, Philippines
}

\begin{abstract}
Article history
Submitted: 26 June 2020

Revised: 2 November 2020

Accepted: 13 November 2020

\section{Keywords}

Criminal Justice

Compassion Fatigue

Coping Skills

PNP First Responders

Descriptive-Correlational

Bacolod City
\end{abstract}

Introduction. Enforcing the law to maintain peace, justice, and order in the community involves the police first responder in situations that are traumatic and cause negative health outcomes. Police are tasked with maintaining peace and helping traumatized victims. Over time, the struggle to alleviate the victims' suffering may come with a cost. Compassion fatigue has multiple negative effects on police well-being and occupational performance. Compassion fatigue refers to the physical and mental fatigue and emotional withdrawal encountered by those who attend for sick or traumatized people over a lengthened period. In contrast, coping skills means investing one's own intentional effort to resolve personal and interpersonal difficulties in order to try to comprehend, reduce, or permit compassion fatigue. The paper describes the extent of compassion fatigue and coping skills of the PNP first responders in Bacolod city. Likewise, it explores the relationship between the Philippine National Police (PNP) first responder's demographics and their compassion fatigue and coping skills. Also, it determines the correlation between compassion fatigue and coping skills of PNP first responders.

Methods. A descriptive-correlational research design was used to assess the extent of compassion fatigue and coping skills of PNP first responders in Bacolod City during the fiscal year 2019-2020. Using purposive sampling, 100 Police first responders participated in the study. Two standardized test questionnaires were used to gather data for this study. Mean, Standard Deviation, and, Pearson product-moment correlation were used to analyze the data.

Results. Compassion fatigue and coping skills are directly related. Regardless of their demographic backgrounds, police officer first responders can have a high extent of coping skills and a high extent of compassion fatigue. Despite the high extent of coping skills, there are still areas that need improvements. Similar can be said in the very high extent of compassion fatigue of police officer first responders. There is a need for scaffolding and support to enhance coping skills to lower their debilitating effects. The findings of the study unveiled that regardless of the demographics, the extent of compassion fatigue as a whole is an extremely high risk, and the extent of coping skills as a whole is high. In relation to the problems of the study, there is no significant relationship between compassion fatigue and demographics, no significant relationship between coping skills and demographics, and no significant relationship between compassion fatigue and coping skills.

Conclusion. It is indicated that even when the PNP first respondents experience difficulties at work and develop negative behavior, they can cope and adjust within the environment, probably with the help of their family, friends, and respective support system. Albeit the respondents achieved a high result in compassion fatigue and extreme stress and trauma are inherent in police work. The significant assumption of this on these professionals could incorporate exhaustion, absenteeism, decreased happiness previously acquired from their job, diminished ability to reach decisions, and others. There would also be a spillover effect on the people they serve to protect, resulting in a decrease in the quality of services rendered. Although police officers are more resilient than the general population, they are only human beings, and it is imperative to enforce a high level of awareness and health maintenance. 
Practical Value of the Paper. The study significantly contributes to the few existing literatures on the Compassion fatigue and Coping skills of PNP first responders and law enforcement in general and is one of the first studies to address such a topic in the country. In addition, the findings of the study provided baseline information to the PNP and mental health professionals in building a foundation in which seminars, workshops, training, and therapies can be provided and enhancing the work performance of the PNP first responders by overcoming compassion fatigue and developing bettercoping strategies.

\section{References}

Agbayani, B., Aurora, P., Trinidad M. Villaflor, T., Villaret, N., \& Hechanova, M.R. (2018). The Role of Filipino Masculine Ideology on the adaptive coping, psychological well-being, and vicarious trauma of first responders. International Journal of Culture and Mental Health, Volume 11, 2018 - Issue 4.

Barren, J. (2005). Use of existential-phenomenological counseling for police officers. Policing: An International Journal of Police Strategies \& Management, 28, 255-268. doi:10.1108/13639510510597898

Berg, A., Hem, E., Lau, B., Ekeberg. (2006). Help-seeking in the Norwegian police service. Journal of Occupational Health, 48, 145-153. doi:10.1539/joh.48.145

Blumenstein, L., Fridell, L., \& Jones, S. (2012). The link between traditional police subculture and police intimate partner violence. Policing an International Journal of Police Strategies and Management 35(1):147-164

Chopko, B. (2011). Walk-in Balance: Training Crisis Intervention Team Police Officers as Compassionate Warriors. Journal of Creativity in Mental Health Volume 6, Issue 4.

Franklin, C. A. (2005). Male peer support and the police culture: Understanding the resistance and opposition of women in policing. Women \& Criminal Justice, 16(3), 1-25.

Grant, H., Lavery, C., Decarlo J. (2019). An Exploratory Study of Police Officers: Low Compassion Satisfaction and Compassion Fatigue. Front Psychol. 2019 Jan 25; 9:2793. doi: 10.3389/fpsyg.2018.02793.

Holahan, C. J., \& Moos, R. H. (1987). Personal and contextual determinants of coping strategies. Journal of Personality and Social Psychology, 52(5), 946-955.

Karlsson, I., Christianson, S. Å. (2006). Police officers involved in a manhunt of mass murder: Memories and psychological responses. Policing: An International Journal of Police Strategies \& Management, 29, 524-540. doi:10.1108/13639510610684746

Patterson, G. (2003). Examining the effects of coping and social support on work and life stress among police officers. Journal of Criminal Justice 31(3):215-226

\section{Correspondence:}

Miguel R. Lim [miguellim035@gmail.com]

https://orcid.org/0000-0002-7131-6147 